\title{
Research on the Predicament and Optimization of the Openness of College Sports Facilities in China
}

\author{
Qiang Luo \\ Xi`an International University, Xi`an, Shaanxi, 700077, China
}

Keywords: colleges and universities; stadiums; open to society; dilemmas.

\begin{abstract}
The stadiums and gymnasiums of universities and colleges not only have to meet the needs of teachers and students in physical education teaching and after-school sports, but also should be open to the society in a planned and organized manner, so as to effectively satisfy the increasing demand of popular sports and fitness of the general public in China. Of course, if gymnasiums in colleges and universities is open to the society, it can also enhance its social benefits, and use scientific and reasonable management and management activities to create corresponding economic benefits. However, the stadiums and gymnasiums of colleges and universities in our country are still facing difficulties in the process of opening to the society, and they need to be optimized. This paper briefly describes the basic nature of college gymnasium open to the society, expounds the necessity of opening university gyms to society, analyzes the predicament of college sports venues facing opening to society, and proposes some countermeasures to further optimize the opening of college sports venues to the society.
\end{abstract}

\section{Introduction}

Compared with the uneven quality of sports resources in the society, our universities and colleges have very strong advantages both in indoor sports venues and in outdoor sports venues. However, if these stadium resources are only used for physical education and training activities for teachers and students of this school, it will undoubtedly cause considerable idleness and waste of stadium resources. On the other hand, if we use fiscal funds to build large-scale social sports stadiums, it will greatly increase the burden on government departments. In order to effectively resolve this contradiction, the utilization rate of university gym facilities should be fully enhanced, and the transformation and upgrading of stadiums and gymnasiums in universities and colleges in China should be vigorously promoted. Therefore, the implementation of efficient stadiums and gymnasiums has become a general trend. However, because of the particularity of the construction and implementation of our university's education and teaching, our university stadiums and gymnasiums encountered many problems after opening up to the society. In view of this, we should conduct in-depth research on the opening-up of sports venues in colleges and universities in China in order to find practical and feasible optimization measures.

\section{The Basic Nature of College Sports Facilities Opening to the Society}

The basis for the openness of stadiums and gymnasiums in China's colleges and universities for society includes the following two aspects: On the one hand, it is the rigid requirements put forward by relevant laws and regulations. Due to the rapid economic and social development in China, modern people are increasingly demanding for physical education based on the continuous increase in material and cultural needs. In particular, the awareness of physical fitness of citizens in large and medium-sized cities that are relatively concentrated in universities and colleges It's generally quite strong. Under normal circumstances, university stadiums are non-operating state-owned assets. The state is the property owner of these venues, and colleges and universities are state-owned asset agents for these sports facilities. Under non-operating conditions, university stadiums are based on normal 
physical education teaching and training activities that do not affect colleges and universities. In the process of opening up to the society, fees may be used to collect fees, but this does not change the original situation. Has a non-operating nature.

\section{The Necessity of College Sports Facilities Opening to the Society}

The first is to enrich the modern leisure and entertainment content. The development of modern science and technology has greatly improved the production efficiency. The use of machinery has replaced manpower, allowing people to gradually get rid of heavy work stress and have more leisure time. At the same time, due to the further improvement of modern people's living conditions, people's pursuit of a healthy lifestyle has become higher than before. Diversified sports have become a healthy lifestyle that people are actively pursuing. It enriches the leisure life of modern people. The implementation of the policy of university stadiums opening to the society will be able to better solve this problem. It will not only solve key venue issues for the city's sports and leisure, but also allow some of the people's leisure and entertainment methods to play cards and alcoholism. And other unhealthy lifestyles have shifted to healthy movements, and the overall quality of sports leisure sports has been effectively improved.

The second is to promote the development of university sports education activities. The opening of university stadiums to the society is also conducive to creating a good physical education teaching atmosphere in the school, and it can also promote the upgrading of old sports education and teaching facilities. Mainly reflected in three points: First is to practically narrow the distance between the university and the nearby community, can promote the integration between the two development, for the university sports education can produce complementary advantages, for college sports teaching reform is very good The role of promotion. The second is that the university stadiums are open to the society, so that people from all walks of life who are interested in sports can carry out leisure sports together. This will also enable the undergraduates to focus more on physical education and to stimulate their enthusiasm of participation in sports than the demands of physical education teachers. Finally, the transformation of the university gymnasium operation form can increase the school's income, and it also helps the school to strive for more financial investment in the construction and maintenance of sports facilities.

\section{The Dilemmas of College Sports Facilities Opening to the Society}

First, the resources of university stadiums are not yet abundant. Facilities and equipment for stadium facilities are important material conditions for promoting physical education teaching and training in our school. In view of the continuous expansion of the enrollment scale of China's universities and the continuous increase in the demand for sports venues by university students, the university stadiums have become more and more nervous, and it has been difficult to fully meet the urgent needs of teachers and students for sports. Therefore, on the basis of advancing the construction of sports venues, each university shall, based on specific conditions, use the school's idle space to implement scientific planning as far as possible, and enrich as much as possible its sports facility resources.

Second, it has caused bad influence to normal physical education in universities. Universities have changed their own sports stadium management mode and implemented opening up to the outside world, which will involve the problem of limited teaching resources. It will surely have a certain degree of influence on the daily physical education teaching of college students. Therefore, university gymnasiums must pay attention to this issue when they are open to the society, and all social openness should be implemented only when normal teaching order is ensured.

Third, it has increased in pressure on security issues. University gymnasiums will also increase security risks in opening up to the society. They mainly include the following two aspects: On the one hand, the personal safety of teachers and students cannot be guaranteed. If social groups are allowed to enter the campus for sports and leisure activities, it is easy to increase campus violence. The 
probability of occurrence has increased the security risks of university teachers and students. On the other hand, there are no specific legal provisions in China. Once university sports venues are exposed to incidents and injuries caused by consumer sports in the opening up of society, schools are often unable to promptly make scientific, rapid, and effective disposals, and there is also a great difficulty in the division of follow-up responsibilities.

Fourth, the quality of stadium managers needs to be improved. The openness of university stadiums to the society poses new challenges for the managers of these venues. Not only should they have strong management capabilities, but they should also have certain emergency handling capabilities to ensure the smooth operation of stadiums. However, from the analysis of the status quo of the management talents of sports stadiums in various universities in our country, there are deficiencies in both professional literacy and practical work ability. A considerable number of sports stadium management personnel management concepts and capabilities are too lagging behind to run the stadium well.

\section{Some Countermeasures to further Optimize the Opening of College Sports Venues to the Society}

First, government departments should continue to increase investment. Under the current environment of rapid economic and social development in China, university stadiums are open to society and cannot leave the support of corresponding funds. In the past, the planning and construction of university stadiums and equipment purchases centered on physical education in the university. After opening up to the society, these venues are required to provide services to a large number of social personnel whose needs are more diversified. Therefore, the venues are set up and equipment is arranged. It is also necessary to make reasonable adjustments so as to attract outsiders to sports and leisure. Therefore, government departments should continue to increase investment in the funds required for the transformation and development of university stadiums. Universities should also use school-industry cooperation to continue to expand financing channels and provide greater financial support for the rational operation of university stadiums. In terms of specific plans, it is necessary to make full use of the operating model of the fitness enterprises in the society. Under the premise of not affecting the daily teaching, the implementation of sub-category planning for sports fitness areas and arranging corresponding rest areas. Of course, for stadiums with a relatively long construction period, special funds will be required to carry out renovations, which will be more fashionable.

Second, the concept of scientific management should be actively innovated. The opening of the university stadiums to the society not only can effectively solve the problem of inadequate sports resources in all walks of life, but also can improve the efficiency of the university's sports resources, improve the university's social visibility, and use the open society-oriented approach to gain a better reputation for the university. Therefore, university administrators must be fully aware of the importance of stadium opening to the society, actively break through the traditional management concepts of stadiums and gymnasiums, and promote the development of university stadiums and gymnasiums from the perspective of promoting the development of social sports. Therefore, the management personnel of university stadiums should base themselves on the laws of the sports market, learn from the operation and operation of social stadiums, and on the premise of rational allocation of their own sports resources, find out the scientific model that is truly suitable for the openness of university stadiums. For example, compared with many social fitness establishments, universities not only have sound fitness establishments, but also have abundant resources for outdoor sports facilities in colleges and universities. University stadium operators must use their own advantages in resources to carry out propaganda on their sports stadiums, so as to attract more social and sports enthusiasts to sports and fitness in university stadiums.

Third, the construction of safety and security mechanisms should be improved. After the university stadiums are opened to the society, they must ensure the personal and property safety of the teacher-student group and the consumers. This requires the university security department to play a 
functional role and intensify its work to ensure that people's property safety will not suffer losses. The government management department must also take the initiative to improve and perfect the legal system to ensure that the interests of consumers and college teachers and students are safeguarded. The openness of university sports venues to society is extremely wide, and it covers many aspects of social life. Therefore, it can be said to be a systemic and complex work that urgently requires relevant departments to cooperate closely. From the perspective of the university's own development, university stadiums should implement scientific planning during the process of opening up to the society, constantly increase consumers' attention to personal safety and effectively avoid security incidents in sports on the basis of fully satisfying the sports needs of consumer groups, to form safety supervision methods for university sports venues that are open to the public.

Fourth, the stadium fee standards should be determined. Because the university gymnasium has special social responsibilities, its most important task is to provide quality services for the physical education teaching and research of the university. Therefore, the operation and management activities of university stadiums and gymnasiums are different from ordinary business management. The university stadiums should not only pursue economic benefits, but also pay attention to the optimal allocation of their own social benefits and fully demonstrate the public welfare characteristics of serving the society. Before implementing management and management activities, university sports venues in our country must base on the foundation of venue facilities and equipment, the development of local economic and social associations, and the actual economic endurance of foreign physical exercise personnel in each university, so as to adhere to the foundation of public welfare and implement reasonable Management and management decisions. University sports venues should, on the basis of ensuring normal physical education and teaching order, be open to different groups of people at different times and effectively improve the economic and social benefits of the school's stadiums.

Fifth, the mechanism for employing sports facilities should be improved. The former university stadiums provide services for university students, so they only serve around education and teaching, and both the object and the content of the service are simple, with daily sports equipment management and stadium hygiene. However, after opening up to the public, the social consumer demand for stadium sports is also more demanding. The increase in equipment usage also promotes the maintenance of facilities and equipment. This places new demands on stadium managers. It is not only required that university stadium management personnel not only have very rich knowledge of sports, but also have strong stadium management capabilities so as to enhance their ability to respond to market competition. Therefore, colleges and universities should improve their personnel system for stadiums and gyms, and effectively change the personnel management mechanism that can only select stadium managers among their staff. The management personnel of stadiums currently in the post should improve the training of the group's management, market knowledge, etc., and promote the updating of stadium management methods.

\section{Conclusion}

To sum up, the stadiums and gymnasiums of universities and colleges are open to the society, which can effectively and effectively alleviate the difficult problem that the masses of the people's fitness needs are continuously improving but the current venues are difficult to meet actual needs. Therefore, it is necessary to further deepen the significance of the openness of stadiums and gymnasiums in institutions of higher learning to society. At present, the ultimate goal of university stadiums opening to society is to share resources, provide the people with more conveniences on the basis of maximizing the value of resources, so that the majority of the people can fully feel the care and warmth of society, get pleasure and get fit in physical fitness. 


\section{Acknowledgement}

This research was financially supported by the External Supply Path of Stadiums and Gymnasiums in Universities in Shaanxi Province from the Perspective of Sports Public Services. And Regular Tasks of Sports Bureau of Shaanxi Province. (Grant NO. 17120).

\section{References}

[1] Yang Zhen, Li Yanling. The Predicament and Optimization Strategy of University Sports Venues in China, Journal of Beijing Sport University, 2013(1).

[2] Gao Jinna. Study on the Present Situation and Countermeasures of the Opening of University Stadiums in Hefei City to the Society, Journal of Huzhou Teachers College, 2014(2).

[3] Qi Zhiyong. Research on the Effective Operation Mechanism of School Gymnasium Opening to Society, Science and Technology Outlook, 2015(22).

[4] Zhai Jinhai \& Peng Chunsheng. Investigation and Analysis on the Current Status of Open University Sports Facilities in Jiangsu, Journal of Yangzhou University (Higher Education Research Edition), 2016(5).

[5] Bai Fuchuan. An Empirical Study on the Opening of University Sports Venues in Wenzhou City to the Society, Contemporary Sport Science and Technology, 2017(29). 